\title{
Estratégias para 0 acompanhamento e avaliação de atividades práticas e saídas de campo em Geociências
}

\author{
Strategies for monitoring and evaluating practical activities of fieldwork in earth sciences \\ Carla de Abreu D'Aquino ${ }^{1} \&$ Jarbas Bonetti ${ }^{2}$
}

\author{
1 Universidade Federal de Santa Catarina, Campus Araranguá. Rodovia Governador Jorge Lacerda, 3201. Jardim das Avenidas - \\ Araranguá - SC. CEP 88900-000. carla.daquino@ufsc.br \\ 2 Universidade Federal de Santa Catarina, Departamento de Geociências, Laboratório de Oceanografia Costeira. Campus Universitário, \\ Florianópolis - SC. CEP 88040-900. jarbas.bonetti@ufsc.com
}

\section{Manuscrito: \\ Recebido: 21/02/2014 \\ Corrigido: 07/10/2014 \\ Aceito: $12 / 12 / 2014$}

Citation: D’Aquino C.A. e Bonetti J. 2015. Estratégias para 0 acompanhamento e avaliação de atividades práticas e saídas de campo em geociências. Terræ Didatica, 11(2):7887. <http://www.ige.unicamp.br/terraedidatica/>.

Keywords: Undergraduate education, Geosciences, extra-class activities
ABSTRACT : The present work emphasizes the monitoring and evaluation of practical activities and field trips, as well as the teaching tools of some disciplines of undergraduate courses in Oceanography and Geography at the Federal University of Santa Catarina. The questionnaires were applied to students and teachers after the end of the activities resulted in their evaluation from the perspective of students and teachers. The protocolization of these activities enabled and fostered its evolution. It was found that the design and quantification of these activities may provide answers in terms of infrastructure, equipment available and achieve learning goals, with an interesting assessment tool for improvement and encouragement of this type of activity within the undergraduate courses in the field of Geosciences.

\section{Introdução}

A facilidade de acesso à tecnologia e a velocidade do aporte de informação aos quais os alunos encontram-se atualmente expostos são fatores geradores de um novo paradigma na educação de ensino superior. Nesse mundo globalizado, a necessidade de diversificação das estratégias de ensino visando a manutenção do interesse dos alunos traz um novo desafio didático.

Segundo Ducrotoy et al. (2000) a educação superior é um meio para motivar e formar alunos com uma sólida base relativa ao processo de produção do conhecimento científico. Tal aprendizado permite a inserção no mercado de trabalho de profissionais conscientes, que se tornarão gestores melhores e mais preparados para os desafios atuais. Ao trazermos a discussão das possíveis estratégias para docência no ensino superior destacamos que, apesar deste ser o nível de ensino que busca a formação profissional de alta qualificação, as estratégias didáticas associadas ao ensino de disciplinas de nível superior nem sempre são suficientemente valorizados institucionalmente. Naturalmente, no processo de aprendizado a atuação do professor universitário é fundamental para a boa formação do aluno, pois além de ser o responsável pela condução das aulas, este deve desempenhar o papel de facilitador, buscando uma integração mais ampla dos estudantes com recursos externos à sala de aula, visando seu melhor aproveitamento acadêmico (Melo e Urbanetz 2009).

Este trabalho foi desenvolvido como parte do pós-doutorado da autora, o qual se dividiu em duas partes: o aprimoramento na análise de dados ambientais de forma espacializada e; outra focada na melhoria do ensino de graduação, conforme previsto no âmbito do projeto REUNI (um programa do governo federal que teve por objetivo ampliar o acesso e a permanência na educação superior em todo o país). Dentro deste contexto, o presente trabalho surgiu do acompanhamento de aulas práticas e saídas de campo de algumas disciplinas de Geociências, procurando incrementar o desenvolvimento de recursos didáticos para as mesmas. Conforme Lopes Junior (2010), por meio da experiência docente e da busca de soluções para diferentes questões do dia a dia o professor aprende ensinando. Para isso são necessárias as constantes renovações com base em discussões teóricas e metodológicas associadas a uma reflexão crítica sobre as transformações mundiais. 
Constante e Vasconcelos (2010) já colocam a importância de atividades práticas no ensino da Geologia. Entretanto, pode-se reconhecer nas Ciências da Terra e do Mar como um todo, o amplo emprego de duas estratégias educacionais com o intuito de complementar a formação do aluno, não só relativa à obtenção de conhecimento científico, como também na geração de uma vivência mais próxima ao objeto de estudo e às práticas profissionais. As "aulas práticas" e "saídas de campo" constituem alternativas fundamentais para o ensino de ciências como Geografia, Geologia, Oceanografia, entre outras. Conforme Lima e Assis (2005) o trabalho de campo se configura como um recurso para o aluno compreender o lugar e o mundo, articulando a teoria à prática, através da observação e da análise do espaço vivido e concebido.

Há uma contínua inserção de tecnologias nas Ciências da Terra, através do uso de sistemas de posicionamento baseados em satélites ou do desenvolvimento de instrumentos que facilitam a amostragem direta das características da coluna d'água, por exemplo. Estas conquistas devem ser levadas, precocemente, ao conhecimento dos alunos, preferencialmente como parte do conteúdo das disciplinas, na forma de aulas práticas e saídas de campo. Uma vez que grande parte das pesquisas em Geociências envolve a coleta de dados, seu tratamento e posterior análise, as atividades apontadas devem ser consideradas recursos fundamentais no ensino superior.

Por serem atividades extraclasse, aulas práticas e saídas de campo envolvem grande planejamento, exigindo do professor um esforço complementar para sua realização. Por exemplo, uma saída de campo de qualquer disciplina que vise a coleta de dados envolve as seguintes etapas gerais: a) escolha do local de estudo; b) verificação do acesso para os alunos; c) logística de transporte (ônibus ou embarcação, se esta for no mar) e preparação instrumental (calibração, seleção dos acessórios); d) elaboração de plano amostral; e) a coleta propriamente dita, envolvendo a participação dos alunos; f) manutenção dos equipamentos utilizados após o retorno; g) auxílio no tratamento e análise dos dados. No caso das aulas práticas, diversas etapas são também necessárias para a realização de uma atividade bem sucedida, envolvendo a) preparação do local ou laboratório didático; b) elaboração de um roteiro de apresentação do método a ser empregado; c) preparação do material (quando necessário) amostras, reagentes e/ ou equipamentos, entre outras.
Essa descrição breve e generalizada já remete ao investimento de tempo e dedicação que é necessário para o desenvolvimento desse tipo de atividade, de forma que muitos professores ficam desestimulados em sua realização ou não conseguem atingir plenamente os objetivos traçados. Com intuito de colaborar com a realização dessas atividades tão apreciadas pelos estudantes e tão importantes na sua formação acadêmica, a confecção de protocolos e roteiros para as aulas práticas e saídas de campo demonstra-se necessária por constituírem um material de apoio à referida organização. A elaboração de roteiros e protocolos de aulas práticas e saídas de campo no âmbito de um grupo de professores é, não só uma facilitadora para o uso desta ferramenta educacional como, também, importante para que não haja atividades sobrepostas nas diferentes disciplinas.

Neste sentido e considerando o exposto, o objetivo principal deste trabalho é discutir a elaboração e atualização de protocolos e roteiros para as aulas práticas e saídas de campo, de disciplinas sob responsabilidade de alguns professores da linha de pesquisa Oceanografia Costeira e Geologia Marinha, vinculada à área de concentração Utilização e Conservação de Recursos Naturais do Programa de Pós-Graduação em Geografia da Universidade Federal de Santa Catarina (UFSC). Os professores desta linha são responsáveis por ministrar diferentes disciplinas para os cursos de graduação em Geografia e Oceanografia, com ênfase em Geografia Física e Oceanografia Geológica. Com a estratégia que será apresentada buscou-se promover a melhoria e a inovação do ensino de graduação, garantindo, ainda, o estreitamento dos laços deste com a pós-graduação.

\section{Abordagem Metodológica}

A organização padronizada de uma saída de campo ou aula prática não exclui a experiência única vivenciada pelo aluno. Conforme Oliveira e Assis (2009), durante a aula em campo o imprevisto poderá mudar todo o rumo estrutural e explicativo do conteúdo programado. Essa é uma das riquezas que ultrapassa o planejamento, os livros didáticos e as avaliações prévias, criando as chamadas "novidades" que devem ser trabalhadas na volta à sala. Cabe ao professor dar essa oportunidade à turma, ciente de que a experiência em campo contribui para a formação do individuo que será futuramente um profissional.

A coleta de dados de campo pode ser definida como a "arte de se fazer medições em posições rela- 
tivas da superfície da Terra e apresentar essas informações gráfica ou numericamente" (Bannister, et al. 1992). Nesse processo, a organização das atividades de campo é parte integrante do ensino de Oceanografia, Geografia e demais geociências.

A primeira etapa foi a identificação de cada atividade prevista e a forma de realização desta por parte do professor. Essa etapa forneceu a dimensão da quantidade de protocolos de aulas práticas e do número de roteiros de campo a serem desenvolvidos. Paralelamente, nessa fase inicial, foi realizado um levantamento bibliográfico a respeito dos métodos, técnicas e softwares empregados nas aulas práticas. Como resultado, foram elaborados roteiros preliminares ou adicionadas sugestões ao procedimento habitualmente realizado pelo professor.

O roteiro preliminar ou o ajustado foi então utilizado pelo professor na disciplina. Após a atividade, foram distribuídos questionários de avaliação a todos os alunos participantes, buscando-se verificar não só o roteiro sugerido, mas a atividade como um todo. Após o recebimento, os questionários foram tabulados e organizados em gráficos com os percentuais de cada resposta. Os resultados foram então encaminhados ao professor responsável e discutidos.

Quando necessário, ajustes foram realizados para então se proceder a elaboração do documento (protocolo ou roteiro) final. Cada uma das etapas envolveu o professor e os alunos na busca do melhor aproveitamento da atividade sugerida. O documento final incluiu ainda os objetivos da atividade, referências ao método, técnicas ou equipamentos utilizados, bem como indicações que auxiliem na organização e tratamento dos dados coletados. Além disso, recomendou leituras complementares que possibilitassem a aproximação da teoria com a prática.

Como são atividades distintas, aulas práticas e saídas de campo são compostas por etapas diferentes durante a sua elaboração por parte do professor, conforme mostra a Figura 1. No caso das saídas de campo, a organização da atividade inicia-se com a escolha do local a se visitar. Devem-se responder algumas perguntas gerais, tais como: "o local se adéqua à logística disponível? Atende ao interesse didático?" para que a fase seguinte se inicie. Definido o local, é interessante e necessário que se faça um levantamento sobre o que já existe de informação a seu respeito. A etapa posterior será selecionar os equipamentos a serem utilizados e, também nessa etapa, verificar a logística de transporte e uso necessária e disponibilidade do equipamento.
Conhecido o local e sabendo-se da disponibilidade de logística e infraestrutura instrumental, segue-se então para a definição das variáveis a serem observadas e da estratégia amostral a ser empregada. Essa etapa pode ser discutida em sala com os alunos, como uma forma dinâmica de interação com o que irão realizar no campo. As estratégias para análise de dados, como indicação de softwares e técnicas a serem empregadas, também devem constar do roteiro, bem como a forma de elaboração do relatório final por parte do aluno. Essa etapa final é também empregada para as aulas práticas.

Nas aulas práticas as atividades possíveis são bastante diversificadas dentro de uma mesma disciplina, mais ainda quando se engloba toda uma área do conhecimento, como no caso de disciplinas introdutórias. Assim sendo, neste trabalho a fase inicial de preparação para a aula prática foi muito diferente para cada disciplina. As quatro etapas apresentadas na Figura 1 representam aspectos gerais a serem seguidos, iniciando-se pela seleção do tema e do material (se for análise laboratorial) ou base de dados, etapa esta que acompanha a teoria ministrada em sala de aula. Posteriormente, se a aula envolver

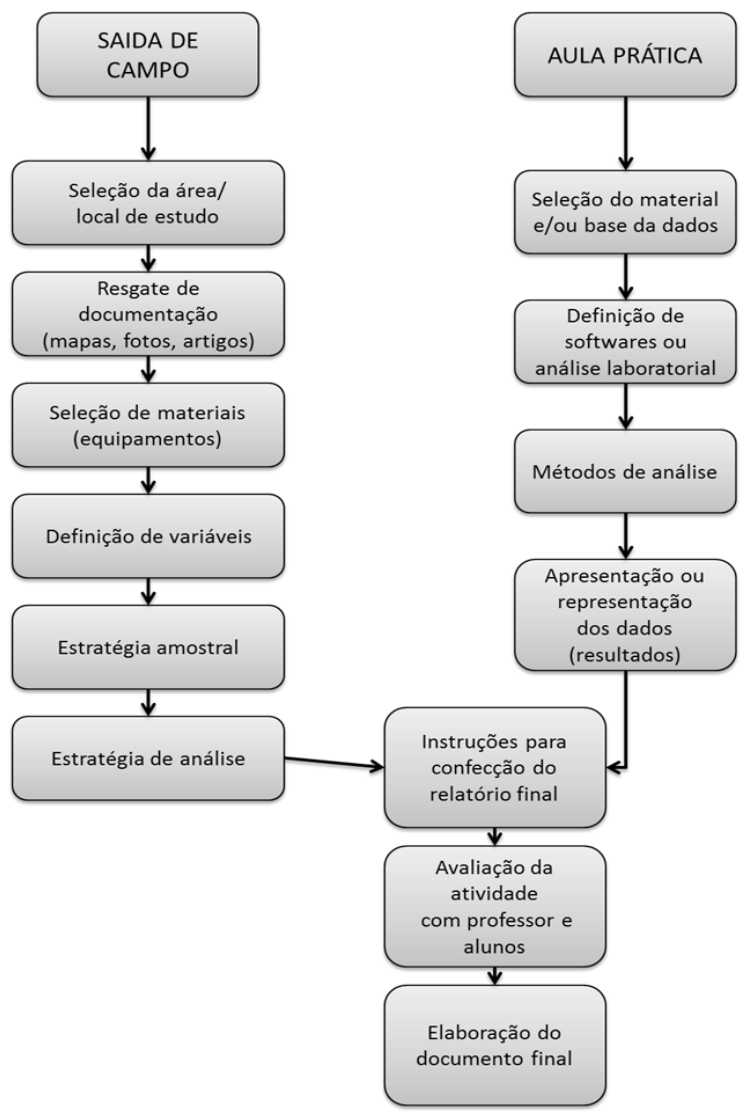

Figura 1. Fluxograma com as etapas de elaboração dos roteiros de saída de campo e protocolos de aula prática 
análise laboratorial, por exemplo, análise granulométrica por peneiramento de uma amostra de sedimentos, procede-se ao detalhamento da mesma, ou ainda à definição de software, no caso de disciplina voltada à análise de dados numéricos ou espaciais. Segue-se então para a seleção e descrição do método e técnicas associadas, apresentação e representação dos resultados/dados, chegando-se às etapas finais, semelhantes às indicadas na elaboração dos roteiros para as saídas de campo.

A formulação e posterior ajuste dos protocolos de aulas práticas e roteiros de saída de campo, conforme método descrito anteriormente envolveu as disciplinas: Sedimentação Marinha (GCN-7003); Recursos Minerais Marinhos (GCN-7014); Evolução e Proteção Costeira (GCN-7941); Análise de Dados (GCN-7008); além da disciplina Geofísica Marinha (GCN-7004) em 2012/2, todas oferecidas para os cursos de Oceanografia e/ou Geografia da Universidade Federal de Santa Catarina - UFSC. A Tabela 1 resume as atividades acompanhadas em cada disciplina e a data de realização das mesmas.

Após a realização das atividades (saída de campo ou aula prática) nas disciplinas, foi aplicada uma avaliação do roteiro ou protocolo preliminar, através de questionário submetido aos alunos (exemplo na Figura 2). Buscou-se responder perguntas relativas à viabilidade e custo das atividades planejadas, cumprimento dos objetivos propostos, motivação e importância para a formação pessoal.

Os questionários foram compostos por perguntas objetivas e por perguntas que permitissem aos alunos expressarem diretamente sua opinião (discursivas). Além delas, foi solicitado ao aluno que desse uma nota à atividade. Os questionários foram compostos por 7 a 10 perguntas, dependen- do da complexidade da atividade. Os mesmo foram aplicados de forma a testar duas estratégias diferentes. A primeira se deu em classe, na aula seguinte à atividade, tendo os questionários sido entregues no início da aula, respondidos imediatamente e entregues ao professor. A segunda estratégia, consistiu da elaboração dos questionários no GoogleDocs (https://docs.google.com) para serem respondidos on-line pelos alunos e disponibilizados por meio de sistema MOODLE da disciplina na forma de link.

As respostas foram posteriormente tabuladas para gerar a estatística correspondente. O passo seguinte foi a reformulação ou não do roteiro ou protocolo e sua disponibilização para uso do professor nas edições seguintes da disciplina.

\section{Resultados e Discussão}

Os resultados obtidos se concentram na experiência de acompanhamento das atividades prática ou de campo, da avaliação do aluno sobre a atividade e do roteiro ou protocolo final que resultou de todo 
o processo. Os resultados serão apresentados separadamente para cada disciplina.

\section{Disciplina GCN 7003 - Sedimentação Marinha}

A interação com a disciplina Sedimentação Marinha na sua edição de 2011 contemplou uma atividade prática de análise granulométrica, ministrada em duas aulas para turmas diferentes (a e b), e uma atividade de campo realizada em dois dias distintos. As aulas práticas envolveram procedimentos laboratoriais para análise de material sedimentar grosso (peneiramento)

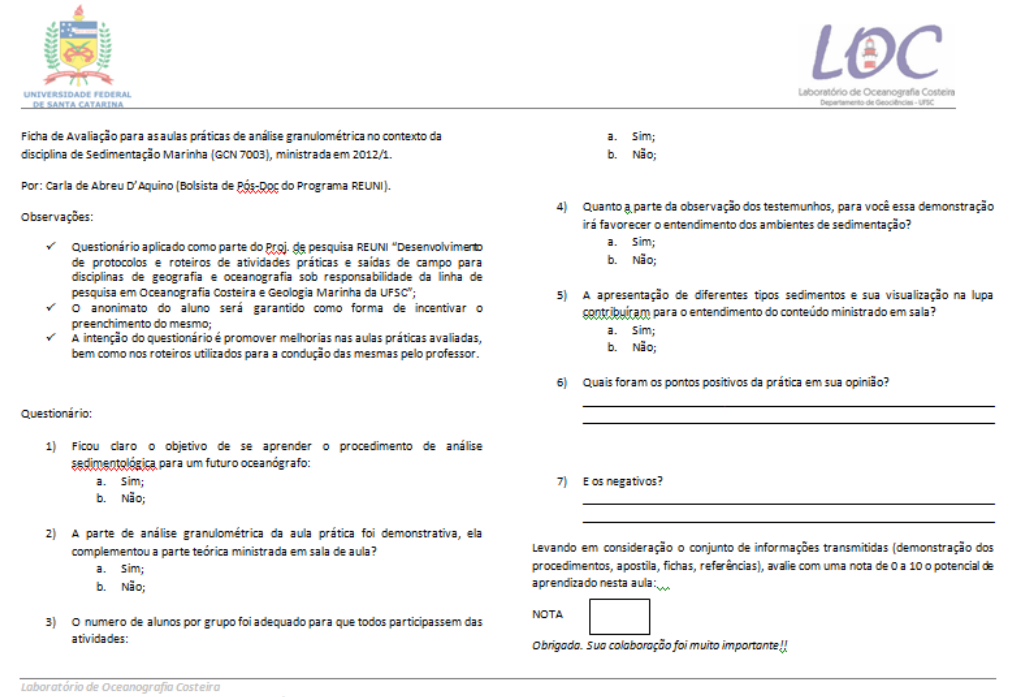

Figura 2. Exemplo de questionário aplicado na disciplina de Análise de dados. e lamas (pipetagem). O laboratório estava equipado com dois jogos completos de peneiras, uma balança de precisão, algumas bacias para lavagem de amostras, uma estufa e um dissecador, além de toda a vidraria necessária aos procedimentos.

Considerando que o curso de graduação em questão havia sido recentemente implementado e contava com sua infraestrutura ainda em construção, foi utilizado um laboratório de pesquisa da Universidade para o desenvolvimento da atividade. Apesar do mesmo ser bem equipado, este não contava com espaço físico adequado para o pleno desenvolvimento da aula, de modo a permitir a participação efetiva dos alunos na análise. Alternativamente optou-se por fazer a aula demonstrativa, a fim de permitir um contato com a técnica em ambiente laboratorial.

Para essa aula já se dispunha previamente de um roteiro de análise, o qual foi adaptado para melhor compreensão dos alunos e disponibilizado em meio digital alguns dias antes de sua realização. A aula foi ministrada e o questionário respondido pelos alunos na aula seguinte, sendo que os resultados refletem os principais desafios superados para a realização da atividade.

Para $100 \%$ dos alunos o roteiro contribuiu para o aprendizado, tendo ficado claro o objetivo de se aprender o procedimento para o seu futuro profissional. Mais de $60 \%$ dos alunos afirmaram que a realização da aula de forma apenas demonstrativa desfavoreceu o aprendizado e que o número de alunos por grupo foi inadequado. Mesmo assim, 60 $\%$ dos alunos sentiram-se aptos a refazer as análises seguindo o roteiro, sem a ajuda do professor.
A manifestação dos alunos quanto à falta de atividade prática pode ser encarada de forma positiva, representando o interesse dos mesmos no procedimento. Mesmo não tendo o formato satisfatório a atividade prática parece ter atingido seus objetivos, já que muitos alunos se manifestaram capazes de seguir o roteiro e de repetir o procedimento sem ajuda. Por outro lado, essa afirmação pode representar o desconhecimento das sutilezas associadas à aplicação da técnica necessária, que pode parecer mais simples na demonstração do que em uma real situação de análise.

Os pontos positivos desta prática, conforme apontado pelos alunos foram o entendimento e o contato com o procedimento analítico, sendo os principais negativos a não condução das análises por parte destes, infraestrutura inadequada e pouco tempo, reforçando uma realidade vivida pelo professor com a falta de laboratórios didáticos para o curso relativamente novo (Oceanografia). 78\% dos alunos consideraram o roteiro bom e sem necessidade de sugestões e $17 \%$ sugeriram que ele fosse exposto em aula teórica anterior à prática.

$\mathrm{Na}$ edição de 2012 a disciplina considerou os resultados obtidos anteriormente e a atividade foi organizada de forma a contemplar uma aula prática, também demonstrativa, porém divida em temas. O roteiro foi revisado, e a partir dele foi criado um fluxograma da análise com fotos para ser apresentado em classe, facilitando o aprendizado.

Antes da aula prática os assuntos foram abordados mais extensivamente em sala de aula, o que refletiu positivamente na avaliação da atividade realizada. Para $100 \%$ dos alunos ficou claro o objetivo de se 
aprender o procedimento de análise granulométrica e foi reconhecido que a parte demonstrativa completou a teórica. Além disso, para $100 \%$ dos alunos a apresentação dos diferentes tipos de sedimento e sua visualização contribuiu para o entendimento do conteúdo ministrado em sala de aula. Para 91\% deles a descrição dos testemunhos favoreceu o entendimento sobre os ambientes de sedimentação.

Observando estes resultados é importante destacar que a aula prática de 2012 foi realizada no Laboratório de Oceanografia costeira da UFSC. O referido laboratório conta com uma infraestrutura instrumental superior, porém voltada para a realização de pesquisas, de forma que os alunos igualmente foram divididos em grupos. Todavia, nesta edição da disciplina 100\% dos alunos alegaram que o número de integrantes por grupo (cerca de 8) foi adequado para que todos participassem. Somado a isso, o fato dos alunos terem sido apresentados de forma mais explícita ao conteúdo, anteriormente em sala de aula, parece ter revertido em um melhor aproveitamento da prática. Foram apontados muitos pontos positivos pelos acadêmicos, porém dois negativos chamaram atenção: pouco tempo e falta de equipamentos para que todos pudessem conduzir o experimento. Isso reflete mais uma vez a importância de se fomentar a criação de laboratórios didáticos para o ensino de Geociências.

Nas duas edições desta disciplina foram realizadas saídas a campo, a fim de se observar diferentes ambientes costeiros de sedimentação e discutir sua relação com aspectos geológicos e processos dinâmicos. Esta atividade não apresentava roteiro ou instrumento guia para os alunos nas edições anteriores. Assim, foi proposto um bloco de campo que contemplou um mapa da área, uma breve descrição de cada ponto visitado, além de um espaço destinado à anotação pelos alunos. Essa ferramenta didática foi disponibilizada aos alunos antes da ida a campo.

A atividade de campo foi realizada com sucesso e os alunos avaliaram a saída em si e também o bloco de notas elaborado. Na primeira edição (2011), 100\% dos alunos declararam que o bloco de campo favoreceu o aprendizado e para $92 \%$ o objetivo da saída de campo para um futuro profissional ficou claro. Para 4\% dos alunos a explicação em cada parada para observação não ficou clara, porém para 100\% deles as dúvidas foram esclarecidas. Para $96 \%$ dos alunos a saída de campo contribuiu para o aprendizado em sala de aula.

Os principais pontos positivos segundo os alunos foram: a explicação dada, o relacionamento entre teoria e prática e a escolha dos pontos. Para $72 \%$ dos alunos não houve pontos negativos, porém para $12 \%$ dos alunos a saída foi muito "corrida" (pouco tempo). Pela avaliação dos acadêmicos percebe-se a aceitação e positividade deste tipo de atividade e a importância de um material didático preparado especialmente para tal. Este fato corrobora a opinião de alguns autores no que se refere às saídas de campo, como destacam Alentejano e Rocha-Leão (2006): "Fazer trabalho de campo representa, portanto, um momento do processo de produção do conhecimento que não pode prescindir da teoria, sob pena de tornar-se vazio de conteúdo, incapaz de contribuir para revelar a essência dos fenômenos geográficos".

$\mathrm{Na}$ edição do primeiro semestre de 2012 a disciplina de Sedimentação Marinha foi além, realizando uma segunda atividade de campo, agora a bordo de embarcação, propiciando aos estudantes de Oceanografia uma experiência de fundamental importância na sua formação. Além da titular da disciplina, outros dois professores foram convidados a participar da atividade, formando assim três estações de trabalho. Os alunos foram divididos em grupos, com cada um dos professores apresentando uma técnica diferente. Para esta atividade o roteiro consistiu de um mapa com a localização dos pontos e de discussões em sala de aula sobre os métodos a serem empregados em campo.

O questionário foi elaborado on-line, utilizando-se o GoogleDocs, e disponibilizado na plataforma Moodle da disciplina. Dos 30 alunos participantes 21 responderam o questionário. A avaliação dos alunos foi muito receptiva, sendo que sete perguntas tiveram $100 \%$ de respostas positivas. Apenas para $5 \%$ dos alunos as explicações sobre o GPS e o CTD (sonda que mede condutividade, temperatura e pressão da água do mar) não ficaram claras. Mais de $50 \%$ dos alunos deram nota 10 para a atividade e a menor nota foi oito. Além disso, vários deles destacaram a participação de mais de um professor como muito favorável. A maioria ressaltou que a prática e o contato com os equipamentos favoreceram o aprendizado e reforçaram a teoria vista em classe. Os pontos "negativos" mencionados foram na verdade solicitações para que ocorressem mais atividades embarcadas no curso.

Finalizando a proposta metodológica, o retorno do professor quanto à participação desta atividade REUNI em sua disciplina foi formalizado por meio de algumas perguntas. A professora responsável pela disciplina Sedimentação Marinha expressou positivamente a participação do projeto dentro da sua 
disciplina: "a iniciativa do projeto foi muito boa e colaborou, sobretudo, com a organização das atividades práticas". A mesma declarou ainda que toda a iniciativa que venha valorizar a didática em sala de aula e motivar os alunos a participarem ativamente das disciplinas e das discussões acadêmicas será muito bem vinda e deve ser continuada.

\section{Disciplina GCN 7014 - Recursos Minerais Marinhos}

Nesta disciplina o desenvolvimento de atividade consistiu no acompanhamento de visita técnica a uma empresa de extração de magnésio não metálico a partir da água do mar. O roteiro utilizado pelo professor apresentava a localização da indústria e varias instruções de comportamento. Por não ser uma atividade que envolvesse um método laboratorial ou uma saída de campo tradicional optou por acompanhar a saída para formular posteriormente um possível roteiro ou protocolo.

Chegando-se ao local foi realizada por parte da empresa uma explanação sobre o histórico daquele tipo de atividade e uma breve explicação do método de extração. Logo a seguir os alunos foram divididos em grupos e visitaram as áreas de produção. Após a visita foram aplicados os questionários para avaliação da atividade. Para 100\% dos alunos a saída de campo contribuiu para o aprendizado em sala de aula. Porém $8 \%$ deles consideraram que a explicação não foi clara, e 32\% ficaram com dúvidas quanto ao processo de extração, alegando que o mesmo não foi devidamente descrito. Considerando que o tema foi abordado anteriormente em sala de aula esse percentual inspirou reflexão.

A maior parte dos alunos deu nota 8 e 9 para a saída de campo, e $28 \%$ concordaram que o ponto positivo foi conhecer o processo de extração. Para $21 \%$ foi conhecer uma possível área de atuação e, para $18 \%$, o ponto positivo da saída de campo foi a possibilidade de relacionar teoria e prática. O principal ponto negativo da saída apontado por 33\% dos alunos foi a explicação pouco clara, seguido da restrição de áreas visitáveis (22\%). Observando também o exposto nas respostas discursivas dos alunos percebe-se que os mesmos receberam grande quantidade de informação. Durante a visita, quando estavam em grupos, dúvidas e questões surgiram, porém parte dos responsáveis indicados pela empresa para apresentar as etapas do processo de extração supostamente não tinha o conhecimento técnico para saná-las.

Focando nesta questão, concluiu-se que não havia muito o que se propor em relação à parte que cabe a empresa, mas no que diz respeito à quantidade de informação, foi proposto ao professor a elaboração de um fluxograma para facilitar a compreensão das etapas do processo de extração. A proposta foi que o fluxograma fosse entregue na empresa, no momento de início da palestra, de forma que os alunos pudessem ouvir a explicação e visualizar o processo, favorecendo o aprendizado.

Em 2012 o fluxograma foi utilizado durante a visita técnica e o resultado do uso deste recurso de apoio didático transpareceu no questionário de avaliação, em que $95 \%$ dos alunos alegaram compreender a explicação. Para $100 \%$ deles, o processo de extração ficou claro, o fluxograma ajudou durante a visita e as dúvidas foram respondidas.

Apesar deste aspecto favorável, os alunos ainda apontaram pontos negativos como: explicação muito rápida durante a visita (8\%) e explicação incompleta na visita com grupos (59\%). Segundo o retorno dado pelo professor sobre a participação do projeto vinculado ao REUNI na sua disciplina, o mesmo achou-a proveitosa e destacou que o fluxograma ajudou igualmente ao pessoal da empresa.

\section{Disciplina GCN 7941 - Evolução e Proteção Costeira}

Esta atividade de campo foi divida em duas etapas, a primeira contemplando dois dias de viagem de ônibus e a segunda, no fim de semana seguinte, um dia inteiro. A disciplina em questão já possuía ferramentas didáticas bastante elaboradas, com mapa e descrição dos pontos. $\mathrm{Na}$ edição de 2011 a saída ocorreu logo após o encerramento oficial do semestre, ficando comprometida a entrega e devolução dos questionários. Focou-se, então, no acompanhamento mais próximo das atividades do professor na questão da logística para a execução da atividade.

$\mathrm{Na}$ edição de 2012 os questionários foram entregues aos alunos após as duas etapas de campo estarem concluídas. Para 100\% dos alunos: ficou clara a importância da saída de campo para sua futura atuação profissional, o roteiro de campo favoreceu o aprendizado, a visualização dos processos em campo complementou o exposto em sala de aula e a saída de campo foi importante como um todo. Uma avaliação muito positiva e que retrata a importância da experiência em campo em Geociências.

Houve apenas dois aspectos criticados: para $4 \%$ dos alunos as dúvidas não foram esclarecidas e para $24 \%$ deles a quantidade de pontos visitados por dia não foi adequada, tendo sido muitos pontos na pri- 
meira etapa e poucos na segunda. A grande maioria dos alunos deu notas entre 8 e 10 para a atividade como um todo.

Esta atividade de campo envolve grande logística preparatória, como definição de local para pernoite, alimentação e grandes deslocamentos. Todavia, com o planejamento antecipado, um roteiro bem preparado e bom conhecimento local por parte do professor foi possível um excelente aproveitamento por parte dos alunos. Confirmou-se assim que o planejamento constitui etapa fundamental da atividade de campo, conforme anteriormente assinalado por diversos autores, como: Gonçalves (2012), Falcão e Pereira (2009), Lacoste (2006), Lima e Assis (2005), entre outros.

\section{Disciplina GCN 7008 - Análise de dados}

Conforme coloca Venturi (2006), num trabalho científico a obtenção de dados nunca é aleatória, mas está sempre vinculada a um objetivo, a uma problemática pré-estabelecida. Além disso, a coleta de dados é parte inicial da pesquisa, seguida de perto pela análise dos dados e sua posterior interpretação. A disciplina Análise de Dados aborda diferentes etapas necessárias para o desenvolvimento de uma pesquisa cientifica, proporcionando aos alunos, além de um contato com ferramentas de análise, uma discussão concreta sobre amostragem, seus métodos e critérios.

O acompanhamento desta disciplina foi um pouco diferenciado, já que metade dela é composta por atividades práticas. Dessa forma foi entregue ao final de cada semestre um questionário avaliando a disciplina como um todo. Para 2011 mais da metade dos alunos $(56 \%)$ consideraram difíceis os temas abordados em aula e $45 \%$ acharam que o material didático era excelente e $44 \%$ bom. Houveram críticas quanto à necessidade de conhecimentos prévios para se acompanhar o conteúdo da disciplina ou complementares durante a realização da mesma, uma vez que os alunos entram em contato direto com a estatística e o software selecionado para análise de dados.

No ano seguinte a disciplina incorporou uma aula diferenciada, apresentando um software alternativo para análise de dados, mostrando exemplos práticos e enfatizando a importância da parte básica que eles enfrentam na disciplina. Essa aula, além de ser um complemento, teve como objetivo motivar os alunos. Nesta edição, 34\% dos alunos consideraram o tema como difícil, a maioria classificando-o como regular (66\%). Eles consideraram o material didático bom a excelente.

A avaliação dos alunos foi bastante positiva se considerarmos essa área do conhecimento como bastante densa em termos de conteúdo, sendo importante não só para aqueles que serão pesquisadores, mas também para os que se inserirem no mercado de trabalho.

\section{Disciplina GCN 7004 - Geofísica Marinha}

A disciplina Geofísica Marinha vinha sendo anteriormente ministrada apenas em sala de aula, principalmente pelas dificuldades logísticas e indisponibilidade de equipamentos para práticas. Com a vinculação do presente projeto à mesma o professor desta disciplina teve a oportunidade de implementar uma saída de campo relacionada a técnicas de levantamento batimétrico em 2012.

O acompanhamento teve início com a preparação da logística para a aula, sobretudo viabilização de aluguel de barco, preparação de equipamentos (sonda e GPS) e seleção de local adequado. Seguiu-se com a inclusão de uma aula para discussão e planejamento do campo, abordando-se a importância do levantamento batimétrico, a legislação vigente para tal e, por fim, o planejamento do campo. Os alunos participaram ativamente desta aula, escolhendo as feições a serem observadas e o local para realização das linhas amostrais.

A saída de campo ocorreu na Lagoa da Conceição e teve a participação de uma professora convidada e de um oceanógrafo que trabalha nesta temática. $\mathrm{Na}$ aula seguinte os alunos responderam ao questionário de avaliação. Esse questionário envolveu cerca de 9 perguntas diretas, considerações positivas e negativas por parte dos alunos e um espaço para uma nota geral. Para 95\% dos alunos ficou claro o objetivo da saída de campo para a futura atuação profissional, para $100 \%$ deles: a experiência de trabalho em uma embarcação favoreceu o aprendizado; a explicação sobre o uso do GPS e a navegação foi clara; o método de utilização da sonda batimetrica foi bem explicado; assim como a importância da medição da maré para o levantamento. $100 \%$ deles também consideraram a participação de mais um professor positiva, tiveram todas as dúvidas esclarecidas e consideraram que a saída a campo irá contribuir para o aprendizado em sala de aula.

Os alunos colocaram como pontos negativos: pouco tempo de duração da atividade, o fato do tempo ter excedido o planejamento, a disponibilidade de poucos equipamentos para muitos alunos, o pouco tempo para análise dos dados e infraes- 
trutura do barco. Isso demonstra a importância que os alunos dão a esse tipo de atividade. Já que esta foi a primeira vez que ocorreu tal saída, vale lembrar que não houve tempo para formulação de um roteiro, o qual deve englobar as etapas de planejamento, execução (uso dos equipamentos) e análise de dados. Este roteiro deverá ser incorporado nas próximas edições da disciplina.

Como pontos positivos, foi declarado: ter-se obtido conhecimento prático do uso dos equipamentos, presença de diferentes professores com experiência na área, ser estimulante "aprender na prática", a participação dos alunos no auxilio à navegação e obtenção do conhecimento das dificuldades que podem ser encontradas em campo. Essa última consideração é talvez uma das mais importantes, já que remete ao verdadeiro aprendizado na "arte de fazer campo", e estimula a busca de soluções rápidas em momentos de crise. Essa qualidade é particularmente importante para oceanógrafos, geógrafos e demais profissionais da Geociências.

Segundo Venturi (2006) o momento do trabalho de campo representa o contato imediato com a realidade, ainda que se possa fazer uso de instrumentos para tal; é o momento de conhecê-la melhor por meio de técnicas de observação e interpretação, instrumentalizadas ou não. $\mathrm{O}$ contato direto com a realidade em campo não significa que se tenha o mesmo controle dos processos que se pode ter em laboratório. No campo, o técnico/cientista está submetido às dinâmicas do objeto que elegeu estudar. De forma que, o planejado em laboratório ou gabinete pode não ocorrer exatamente como se esperava. Isto significa que o planejamento do campo da pesquisa requer certa flexibilidade por parte do pesquisador (Venturi, 2006).

O que se pretende aqui é destacar o que já havia sido observado por Lacoste (2006): para a maioria dos estudantes "a experiência da pesquisa se limita a isto; a este exercício suplementar de reprodução de conhecimentos já elaborados sem que tenham tomado consciência das possibilidades que teriam de produzir, por si mesmos, elementos de um saber novo". Daí a importância da aprendizagem proporcionada pelo trabalho de campo, que constitui uma das reivindicações principais dos estudantes de cursos ligados às Geociências. Desta forma as aulas práticas e saídas de campo tem um papel diferenciado no ensino uma vez que mostram um novo leque de possibilidades aos alunos, independentemente de como atuarão no futuro, como professores, pesquisadores ou profissionais técnicos.

\section{Considerações Finais}

No estudo dos processos costeiros o contato com o meio é fundamental no entendimento da complexidade das forçantes que ali atuam. Conforme Bell et al. (2003) aulas que empregam dados ambientais genuínos podem aumentar a habilidade dos estudantes em entenderem os conceitos científicos fundamentais. Complementar a isso, o contato com procedimentos de coleta e tratamento de dados ambientais é fundamental na formação de profissionais que atuam no campo, tanto Geógrafos quanto Oceanógrafos, entre outros. A atividade prática como instrumento para os alunos desenvolverem a capacidade observacional e curiosidade cientifica, por meio da experimentação de ambientes e aplicação de técnicas reais de investigação, é uma ferramenta reconhecidamente importante nesta etapa de aprendizado. Tais atividades auxiliam no entendimento do conteúdo teórico ministrado em sala de aula, favorecendo o relacionamento entre a teoria e a observação.

Todavia, o desenvolvimento das atividades práticas e de campo demanda preparo, organização e logística que exigem do professor que se dispõe a utilizar esses recursos, um tempo adicional para sua preparação. Este é um gargalo particularmente importante do sistema educacional superior brasileiro, que apresenta grande déficit de técnicos de laboratório e não prevê a existência de uma classe real de "auxiliares de ensino" que, em início de carreira e com menor carga de responsabilidades administrativas e de orientação, poderiam atuar junto a um professor mais experiente na organização das atividades didáticas de caráter prático. Neste sentido, a sistematização destas em protocolos e roteiros de campo favorece o bom aproveitamento dos alunos. Além disso, as atividades práticas e de campo se tornam mais atrativas para os professores já que, uma vez estruturadas, demandarão menor tempo de planejamento. Complementarmente, deve-se destacar que a aplicação de questionários possibilitou concretamente a implantação de duas alterações em semestres posteriores que repercutiram positivamente nas avaliações das atividades realizadas.

Um roteiro organizado para o desenvolvimento dessas atividades auxilia também na padronização dos dados coletados, podendo a atividade curricular resultar em uma pesquisa de iniciação científica após alguns semestres, alimentando um banco de dados geoambiental. Além dos aspectos já citados, a esquematização e quantificação dessas atividades 
poderão trazer respostas em termos de infraestrutura e equipamentos disponíveis para tal, sendo uma ferramenta interessante de avaliação dos recursos necessários para os cursos de graduação. Ao observar esse conjunto de aspectos pode-se concluir que a estruturação de aulas práticas e saídas de campo contribui com as atividades docentes dos professores e o aprendizado dos alunos.

Considerando a avaliação dos alunos a respeito das atividades, dos roteiros e protocolos criados percebe-se um incremento, de um semestre para outro, no interesse e aproveitamento destes. Desta forma, sugere-se principalmente aos docentes um esforço extra na preparação do material didático de apoio a atividade que se pretende realizar, seja ela de campo ou aula prática, bem como a realização de uma posterior avaliação, com vistas à busca de excelência no ensino das Geociências.

\section{Referências}

Alentejano P.R.R., Rocha-Leão O.M. 2006. Trabalhos de campo: uma ferramenta essencial para os geógrafos ou um instrumento banalizado? São Paulo, Bol. Paul. Geogr., (84):51-67.

Bannister A., Raymond S., Baker R. 1992. Surveying. 6. ed. Longman Scientific \& Technical. 428p.

Bell, W.H., Fowler, E.M., Stein, J.A. Coastal seas as a context for science teaching: a lesson from Chesapeake Bay. Mar. Pollut. Bull., 47:253-259, 2003.

Constante A., Vasconcelos C. 2010. Atividades lúdico-práticas no ensino da geologia: complemento motivacional para a prendizagem. Terrae Didatica,
6(2):101-123. URL: http://www.ige.unicamp.br/ terraedidatica. Acesso 07.03.2013.

Ducrotoy J.P., Shasti S., Williams P. 2000. Coastal sciences and management: the need for networking in higher education. Ocean Coast. Manag., 43:427444.

Falcão W.S., Pereira T.B. 2009. A aula de campo na formação crítico/cidadão do aluno: uma alternativa para o ensino de geografia. In: Enc. Nac. Prát. Ens. Geografia, 10, Porto Alegre, 2009. Anais... Porto Alegre. ENPEG. p. 1-21.

Gonçalves T.E. 2012. Experiências e vivências no trabalho de campo como ferramenta de ensino-aprendizagem em Geografia Regional. Boa Vista: ACTA Geogr., 6(11):153-160.

Lacoste Y. 2006. A pesquisa e o trabalho de campo: um problema político para os pesquisadores, estudantes e cidadãos. São Paulo, Bol. Paul. Geogr., (84):77-92.

Lima V.B., Assis L.F. 2005. Mapeando alguns roteiros de trabalho de campo em Sobral (CE): uma contribuição ao ensino de Geografia. Sobral: Rev. Casa Geogr. Sobral., 6/7(1).

Lopes JR. W.M. 2010. Os diferentes saberes na formação do professor de Geografia. Boa Vista: ACTA Geogr., 4(7):169-183.

Melo A., Urbanetz S.T. 2009. Organização e Estratégias Pedagógicas. Ed. IBPEX. 204p.

Oliveira C.D.M., Assis R.J.S. 2009. Travessias da aula em campo na geografia escolar: a necessidade convertida para além da fábula. São Paulo: Educ. Pesq., 35(1):195-209.

Venturi L.A.B. 2006. O papel da técnica no processo de produção científica. São Paulo: Bol. Paul. Geogr., (84):69-76.

RESUM0 : 0 presente trabalho destaca o acompanhamento e avaliação de atividades práticas e saídas de campo, bem como suas ferramentas didáticas, junto a algumas disciplinas dos cursos de graduação de Oceanografia e Geografia da Universidade Federal de Santa Catarina. A aplicação de questionários aos alunos e professores após a realização das atividades resultou na avaliação das mesmas sob a perspectiva dos alunos e professores. A protocolização das atividades viabilizou e favoreceu sua evolução. Foi possível constatar que a esquematização e quantificação de atividades poderão trazer importantes respostas em termos de infraestrutura, equipamentos disponíveis e alcance dos objetivos didáticos, sendo uma ferramenta interessante de avaliação para melhoria e incentivo deste tipo de atividade dentro dos cursos de graduação na área da Geociências.

PALAVRAS-CHAVE: Ensino de graduação, Geociências, atividades extra-classe 